\title{
Wake-Up Stroke versus Stroke with Known Onset Time: Clinical and Multimodality CT Imaging Characteristics
}

\author{
Jan W. Dankbaar ${ }^{a}$ Henri P. Bienfait ${ }^{d}$ Coen van den Berg ${ }^{a}$ Edwin Bennink ${ }^{a} b$ \\ Alexander D. Horsch ${ }^{a}$ Tom van Seeters ${ }^{a}$ Irene C. van der Schaafa \\ L. Jaap Kappelle ${ }^{c}$ Birgitta K. Velthuis ${ }^{a}$ on behalf of the DUST investigators \\ aDepartment of Radiology, University Medical Center Utrecht, Utrecht, The Netherlands; ${ }^{b}$ Image Sciences Institute, \\ University Medical Center Utrecht, Utrecht, The Netherlands; ${ }^{\circ}$ Department of Neurology and Neurosurgery, Brain \\ Center Rudolf Magnus, University Medical Center Utrecht, Utrecht, The Netherlands; ${ }^{d}$ Department of Neurology, \\ Gelre Hospital Apeldoorn, Apeldoorn, The Netherlands
}

\section{Keywords}

Acute ischemic stroke · Acute stroke imaging ·

Computed tomography - Wake-up stroke

\begin{abstract}
Background: Current guidelines for the treatment of acute ischemic stroke are mainly based on the time between symptom onset and initiation of treatment. This time is unknown in patients with wake-up stroke (WUS). We investigated clinical and multimodality CT imaging characteristics on admission in patients with WUS and in patients with a stroke with a known onset time. Methods: All patients were selected from a large prospective cohort study (Dutch acute stroke study). WUS patients last seen well $>4.5$ and $\leq 4.5 \mathrm{~h}$ were separately compared to patients with a known onset time $\leq 4.5 \mathrm{~h}$. In addition, WUS patients with a proximal occlusion of the anterior circulation last seen well $>6$ and $\leq 6 \mathrm{~h}$ were
\end{abstract}

\begin{tabular}{ll}
\hline KARGER & ( ) 2018 The Author(s) \\
Published by S. Karger AG, Basel Openger \\
E-Mail karger@karger.com & This article is licensed under the Creative Commons Attribution- \\
www.karger.com/ced & NonCommercial-NoDerivatives 4.0 International License (CC BY- \\
NC-ND) (http://www.karger.com/Services/OpenAccessLicense). \\
Usage and distribution for commercial purposes as well as any dis- \\
tribution of modified material requires written permission.
\end{tabular}

separately compared to patients with a known onset time $\leq 6 \mathrm{~h}$ and a proximal occlusion. National Institute of Health Stroke Score, age, gender, history of atrial fibrillation, noncontrast CT (NCCT) Alberta Stroke Program Early CT Score (ASPECTS), CT-perfusion abnormalities, proximal occlusions, and collateral filling on CT angiography were compared between groups using the Mann-Whitney $U$ test and Fisher's exact test. Results: WUS occurred in 149/1,393 (10.7\%) patients. Admission clinical and imaging characteristics of WUS patients last seen well $>4.5 \mathrm{~h}(n=81)$ were not different from WUS patients last seen well $\leq 4.5 \mathrm{~h}(n=68)$. Although WUS patients last seen well $>4.5 \mathrm{~h}$ had a significantly lower NCCT ASPECTS than patients with a known time of stroke symptom onset of $\leq 4.5 \mathrm{~h}(n=1,026), 85.2 \%$ had an NCCT ASPECTS $>7$ and $75 \%$ had a combination of favorable ASPECTS $>7$ and good collateral filling. There were no statistically significant differences between the admission clinical and imaging characteristics of WUS patients with proximal occlusions last
Jan W. Dankbaar

Department of Radiology (E01.132)

University Medical Center Utrecht

PO-Box 85500, NL-3508 GA Utrecht (The Netherlands)

E-Mail j.w.dankbaar@umcutrecht.nl 
seen well $>6 \mathrm{~h}(n=23)$, last seen well $\leq 6 \mathrm{~h}(n=40)$, and patients with a known time to stroke symptom onset $\leq 6 \mathrm{~h}$ ( $n=$ 399). Of all WUS patients with proximal occlusions last seen well $>6$ h, only $4.3 \%$ had severe ischemia (ASPECTS $<5$ ), 13 (56.5\%) had ASPECTS $>7$ and good collateral filling. Conclusions: There are only minor differences between clinical and imaging characteristics of WUS patients and patients who arrive in the hospital within the time criteria for intravenous or endovascular treatment. Therefore, CT imaging may help to identify WUS patients who would benefit from treatment and rule out those patients with severe ischemia and poor collaterals.

(C) 2018 The Author(s)

Published by S. Karger AG, Basel

\section{Introduction}

The current guideline to start treatment with intravenous tissue plasminogen activator (IV-rtPA) for acute ischemic stroke (AIS) patients is based on the time between symptom onset and initiation of treatment. Administration of IV-rtPA is recommended for patients with AIS presenting within $4.5 \mathrm{~h}$ after symptom onset [1]. In patients with a proximal occlusion of the intracranial carotid artery up to the $\mathrm{M} 2$ branch of the middle cerebral artery (MCA), endovascular treatment (EVT), such as a thrombectomy, has been shown beneficial up to $6 \mathrm{~h}$ after symptom onset. If there is moderate to good collateral filling and a favorable Alberta Stroke Program Early CT Score (ASPECTS), with a lower limit ranging from 5 to 7 , EVT can be considered up to $12 \mathrm{~h}$ after symptom onset [2]. A recent trial has even shown that patients can be selected for EVT up to $24 \mathrm{~h}$ when using MR DWI or CTperfusion (CTP) $[3,4]$.

Between 8 and $28 \%$ of patients with ischemic stroke notice the symptoms of their stroke when they wake (wake-up stroke [WUS]) [5-8]. In these patients, the exact duration of the symptoms is not known and symptom onset is calculated from the moment when the patient was last seen well [5]. As a result, most WUS patients are not eligible for IV-rtPA or EVT [9]. However, if a patient would wake up because of the stroke, IV-rtPA or EVT might still be beneficial. Imaging may help to identify WUS patients who would still benefit from treatment and rule out patients with already severe ischemia.

The purpose of this study is to compare clinical and imaging characteristics on admission between WUS patients and patients who were either eligible for intravenous or endovascular stroke treatment.

Similarities in Wake-Up and Known Onset Stroke

\section{Methods}

\section{Study Population}

All patients were selected from a prospective multicenter observational cohort study in the Netherlands (the Dutch acute stroke study [DUST]) between May 2009 and August 2013 [10]. Patients, older than 18 years, with symptoms of AIS were included if they presented to the emergency department within $9 \mathrm{~h}$ after symptom onset and had a National Institute of Health Stroke Score (NIHSS) of at least 2, or 1 if an indication for IV-rtPA is present (e.g., isolated aphasia). Patients were excluded if they had an intracranial hemorrhage or another diagnosis that explained the symptoms on NCCT, known renal dysfunction, or contrast allergy. All patients underwent a non-contrast CT (NCCT), CTP and CT angiography (CTA) on admission [11]. The local medical ethics committees of the participating centers approved the study protocol. All patients or next of kin gave written informed consent, unless a patient died before consent could be obtained, in that case the need for consent was waived by the medical Ethics Committee.

For the current study, patients were excluded if it was unclear whether a patient awoke with stroke symptoms. Patients were also excluded if the NCCT or CTA could not be evaluated, since these are the modalities that are frequently used for EVT selection.

\section{Patient Characteristics}

Time since symptom onset was determined for all patients. For patients with WUS, the time since symptom onset was based on the time since the patient was last seen well.

In all patients, age, gender, previous history of atrial fibrillation, and NIHSS were recorded. After 3 months, the modified Rankin Scale was determined. A poor functional outcome was defined as a modified Rankin score of $>2$ at 90 day follow-up.

\section{Imaging Protocol}

An NCCT and CTP of the brain, and CTA of the cervical and cerebral arteries, were performed at admission in all patients [10, 11]. Multidetector CT scanners, ranging from 40 to 320 detectors, were used for all imaging studies (Philips, Siemens, General Electric, Toshiba).

The NCCT was acquired with $120 \mathrm{kV}, 300-375 \mathrm{mAs}$ at a slice thickness of $0.625 \mathrm{~mm}$ and reconstructed at $5 \mathrm{~mm}$.

The CTP was acquired with $80 \mathrm{kV}$ and $150 \mathrm{mAs}$ per rotation at a slice thickness of $0.625 \mathrm{~mm}$ and reconstructed at $5 \mathrm{~mm}$. It involved successive gantry rotations in cine mode (every $2 \mathrm{~s}$ for $50 \mathrm{~s}$ and 6 additional rotations $30 \mathrm{~s}$ apart) during intravenous administration of $40 \mathrm{~mL}$ of nonionic contrast material followed by $40 \mathrm{~mL}$ of saline with a flow of $6 \mathrm{~mL} / \mathrm{s}$. The CTP coverage ranged from $40 \mathrm{~mm}$ to full brain coverage, including at least the ganglionic and supraganglionic regions to ensure inclusion of the ASPECTS levels [10, 11].

The CTA was acquired from the aortic arch to the vertex at using $50-70 \mathrm{~mL}$ of intravenous contrast followed by $40 \mathrm{~mL}$ of saline, with a flow of $6 \mathrm{~mL} / \mathrm{s}$.

\section{Imaging Evaluation}

On the NCCT, the ASPECTS score or pc-ASPECTS for posterior circulation strokes was determined $[12,13]$. For the analyses, the pc-ASPECTS was dichotomized with a cutoff value of 7 , which is known to be a discriminator of outcome for patients treated with intravenous thrombolysis [12], and with a cutoff value of 5, which has been used in one trial to select patients for EVT [14].

Cerebrovasc Dis 2018;45:236-244 
On the CTP (if available), the Cerebral Blood Volume and Mean Transit Time was automatically calculated using commercially available software for CTP (Extended Brilliance Workstation 4.5; Philips Healthcare) and in-house developed perfusion software applying a bSVD algorithm [15]. The Cerebral Blood Volume and Mean Transit Time parameter maps were visually classified using the ASPECTS/ pc-ASPECTS score [16]. The penumbra and infarct core volume within the whole scan range were quantified with the in-house software using a Tmax $>6 \mathrm{~s}$ for the total ischemic area and a relative cerebral blood flow (CBF) threshold of $30 \%$ to differentiate penumbra from infarct $[17,18]$.

For all WUS patients and patients eligible for IV-rtPA, it was determined whether the penumbra size was $>20 \%$ of the ischemic area [19].

For all WUS patients and patients with a proximal occlusion of the anterior circulation eligible for EVT, it was additionally determined whether the mismatch between the total ischemic area and the infarct core was more than 1.2 [20] or more than 1.8 [3], and whether the infarct core volume was $\leq 50 \mathrm{~mL}$ [4]. Patients with no perfusion deficit were grouped in the favorable mismatch groups.

On the CTA, the intracranial thrombus location, the clot burden score (CBS), and collateral filling were determined. Proximal occlusions ranged from the intracranial internal carotid artery to the M2-branch of the MCA [2]. The CBS was assessed in the anterior circulation of the symptomatic hemisphere by subtracting occluded vessel segments from the maximum score of 10 . For the analyses, the CBS was dichotomized at 6 [21].

Collateral filling was graded on $10 \mathrm{~mm}$ CTA MIP images: $0=$ absent; $1=<50 \%$ filling; $2=50-<100 \%$ filling; $3=100 \%$ filling [21] These scores were dichotomized into 2 categories: poor collateral filling (0-1) and good collateral filling (2-3). Patients without an occlusion were considered to have good collateral filling.

All imaging data were analyzed by one of 3 observers (I.C.S., B.K.V., and J.W.D.), all with more than 5 years of experience in stroke imaging.

\section{Statistical Analysis}

WUS patients who were last seen well $>4.5 \mathrm{~h}$ were compared to WUS patients last seen well $\leq 4.5 \mathrm{~h}$ and patients with a known time of symptom onset $\leq 4.5 \mathrm{~h}$, since this is the time limit for IV-rtPA.

Additionally, WUS patients with a proximal occlusion of the anterior circulation who were last seen well $>6 \mathrm{~h}$ were compared to WUS patients with a proximal occlusion last seen well $\leq 6 \mathrm{~h}$ and patients with a proximal occlusion and a known time of symptom onset $\leq 6 \mathrm{~h}$, since this is a frequently used time limit for EVT.

Categorical variables were analyzed using Fisher's exact tests. The distribution of continuous variables was assessed with the Kolmogorov-Smirnov normality test. As all the continuous variables had a non-normal distribution, they were compared using the Mann-Whitney U test. Numbers and percentages for each variable were calculated. The median and interquartile range was noted for every continuous variable.

\section{Results}

Of the 1,393 patients in the DUST, $1,159(83.2 \%)$ had a known time of stroke symptom onset, $149(10.7 \%)$ had a WUS, and 85 patients (6.1\%) had an unwitnessed day- time stroke. These 85 patients were excluded from further analyses. In addition, 20 patients with known time of stroke symptom onset were excluded because either the admission NCCT $(n=1)$ or CTA $(n=19)$ imaging data were insufficient. Of the remaining 1,139 patients with a known time of stroke symptom onset, 1,026 (90\%) were imaged within $4.5 \mathrm{~h}$ and 399 patients (35\%) who also had a proximal occlusion of the anterior circulation were imaged within $6 \mathrm{~h}$ after symptom onset. Of the 149 WUS patients, 81 were last seen well $>4.5 \mathrm{~h}$. A proximal intracranial occlusion of the anterior circulation was seen in 63 (42\%) WUS patients of whom 23 were last seen well $>6$ h.

Table 1 shows 2 comparisons: (1) the comparison between WUS patients imaged within $4.5 \mathrm{~h}$ after last seen well $(n=68)$ and WUS patients imaged $>4.5 \mathrm{~h}$ after last seen well $(n=81)$, and (2) the comparison between WUS patients imaged $>4.5 \mathrm{~h}$ after last seen well and patients imaged within $4.5 \mathrm{~h}$ after a known time of stroke symptom onset $(n=1,026)$.

\section{WUS Patients Imaged within 4.5 versus $>4.5 \mathrm{~h}$ after}

\section{Last Seen Well}

Except for the difference in IV rtPA use and the time since last seen well, there were no statistically significant differences in clinical and imaging characterization admission.

\section{WUS Patients Imaged $>4.5$ h after Last Seen}

Well versus Patients with Known Time of Stroke

Onset $<4.5 \mathrm{~h}$

The $>4.5 \mathrm{~h}$ WUS patients were younger (median age of 65 vs. $69, p=0.046)$. The NCCT ASPECTS score was significantly lower (median ASPECTS of 10 vs. 10, $p=$ $0.001)$. There was no significant difference in severe ischemic changes, with ASPECTS $<5$ (4.9vs. $2.4 \%, p=0.062$ ). Of all $>4.5 \mathrm{~h}$ WUS patients, 69 (85.2\%) had NCCT ASPECTS $>7$ and 61 (75\%) had a combination of favorable ASPECTS $>7$ and good collateral filling $(>50 \% \mathrm{MCA}$ territory). Of the $>4.5 \mathrm{~h}$ WUS patients, nearly all (99\%) had a penumbra size $>20 \%$ of the ischemic area within the scan range.

Table 2 shows 2 comparisons: (1) the comparison between WUS patients with a proximal occlusion of the anterior circulation imaged $\leq 6 \mathrm{~h}$ after last seen well $(n=40)$ and $>6 \mathrm{~h}(n=23)$, and (2) the comparison between $>6 \mathrm{~h}$ WUS patients with a proximal occlusion of the anterior circulation and patients imaged within $6 \mathrm{~h}$ after a known time of stroke symptom onset with a proximal occlusion of the anterior circulation $(n=399)$. 
Table 1. Comparison between WUS and patients who had a CT-scan $\leq 4.5 \mathrm{~h}$ after known symptom onset

\begin{tabular}{|c|c|c|c|c|c|}
\hline & $\begin{array}{l}\leq 4.5 \mathrm{~h} \\
\text { WUS }(n=68)\end{array}$ & $\begin{array}{l}>4.5 \mathrm{~h} \text { WUS } \\
(n=81)\end{array}$ & $p$ value* & $\begin{array}{l}\text { Known onset } \\
\text { stroke with } \\
\mathrm{CT} \leq 4.5 \mathrm{~h} \\
(n=1,026)\end{array}$ & $p$ value** \\
\hline Age, years, median (IQR) & $70(61-78)$ & $65(56-75)$ & 0.107 & $69(58-78)$ & 0.046 \\
\hline Gender, female, $n(\%)$ & $27(39.7)$ & $37(45.7)$ & 0.509 & $427(41.6)$ & 0.485 \\
\hline Minutes between last seen well and CT, median (IQR) & $135(135-153)$ & $450(315-450)$ & 0.000 & $99(68-135)$ & 0.000 \\
\hline IV-rtPA, $n(\%)$ & $33(48.5)$ & $4(4.9)$ & 0.000 & $750(73.1)$ & 0.000 \\
\hline $\mathrm{EVT}, n(\%)$ & $3(4.5)$ & $4(4.9)$ & 1.000 & $67(6.5)$ & 1.000 \\
\hline \multicolumn{6}{|l|}{ Non-contrast CT findings } \\
\hline NCCT ASPECTS, median (IQR) & $10(10-10)$ & $10(9-10)$ & 0.206 & $10(10-10)$ & 0.001 \\
\hline NCCT ASPECTS $\leq 7, n(\%)$ & $9(13.2)$ & $12(14.8)$ & 0.818 & $86(8.4)$ & 0.066 \\
\hline CBS, median (IQR) & $10(6-10)$ & $10(8-10)$ & 0.982 & $10(8-10)$ & 0.250 \\
\hline Anterior circulation CBS $>6, n(\%)$ & $50(73.5)$ & $64(79.0)$ & 0.445 & $846(82.5)$ & 0.450 \\
\hline \multicolumn{6}{|l|}{ CT perfusion findings ${ }^{\dagger}$} \\
\hline CBV ASPECTS $\leq 7, n(\%)$ & $12(19.4)$ & $22(28.3)$ & 0.241 & $215(22.3)$ & 0.261 \\
\hline MTT ASPECTS $\leq 7, n(\%)$ & $24(38.7)$ & $35(45.5)$ & 0.491 & $383(39.8)$ & 0.336 \\
\hline Penumbra size within scan range, $\mathrm{mL}$, median (IQR) & $18.8(6.3-59.4)$ & $26.1(10.7-51.2)$ & 0.612 & $23.4(6.7-58.7)$ & 0.647 \\
\hline Infarct core size within scan range, mL, median (IQR) & $26.2(16.0-50.8)$ & $28.4(16.7-65.9)$ & 0.623 & $25.9(14.3-53.1)$ & 0.363 \\
\hline Penumbra size $>20 \%$ of ischemic area & & & & & 0.423 \\
\hline within scan range, $n(\%)$ & $56(98)$ & $65(98.5)$ & 1.000 & $805(99.3)$ & \\
\hline \multicolumn{6}{|l|}{ Clinical outcome } \\
\hline mRS $>2$ after 3 months, $n(\%)$ & $23(33.8)$ & $32(40.0)$ & 0.496 & $370(36.6)$ & 0.549 \\
\hline
\end{tabular}

There were no statistically significant differences in admission clinical and imaging characteristics of the 3 groups. Only 1 (4.3\%) of the $>6 \mathrm{~h}$ WUS patients with a proximal occlusion had severe ischemia (ASPECTS $<5$ ), and 13 (56.5\%) had ASPECTS $>7$ and good collateral filling. Sixtyone percent of the $>6 \mathrm{~h}$ WUS patients had a mismatch of more than 1.2 and $44 \%$ a mismatch of more than 1.8 .

The differences in NCCT ASPECTS between WUS patients and patients with a known time of stroke symptom onset are illustrated in Figure 1.

Figures 2 and 3 show examples of a WUS patient last seen well $>4.5 \mathrm{~h}$ with favorable imaging findings for treatment and a patient with known time to symptom onset $\leq 4.5 \mathrm{~h}$ with unfavorable imaging findings.

Similarities in Wake-Up and Known Onset Stroke

\section{Discussion}

In the DUST cohort, one in 10 patients woke up with symptoms of acute stroke. Almost half of the WUS patients woke up within the established treatment time window of IV-rtPA treatment and almost two thirds within a $6 \mathrm{~h}$ time window for EVT. Our results show that there is no difference in admission clinical and imaging characteristics between WUS patients last seen well within the time limit for IV-rtPA or EVT and WUS patients last seen well outside of this time window. Compared to patients with a known time of stroke symptom onset who were imaged within $4.5 \mathrm{~h}$, WUS patients last seen well $>4.5 \mathrm{~h}$ had significantly more ischemic changes on NCCT (low-

Cerebrovasc Dis 2018;45:236-244 239 
Table 2. Comparison between WUS with a proximal occlusion in the anterior circulation, and patients with a proximal occlusion of the anterior circulation and a CT $\leq 6 \mathrm{~h}$ after known symptom onset

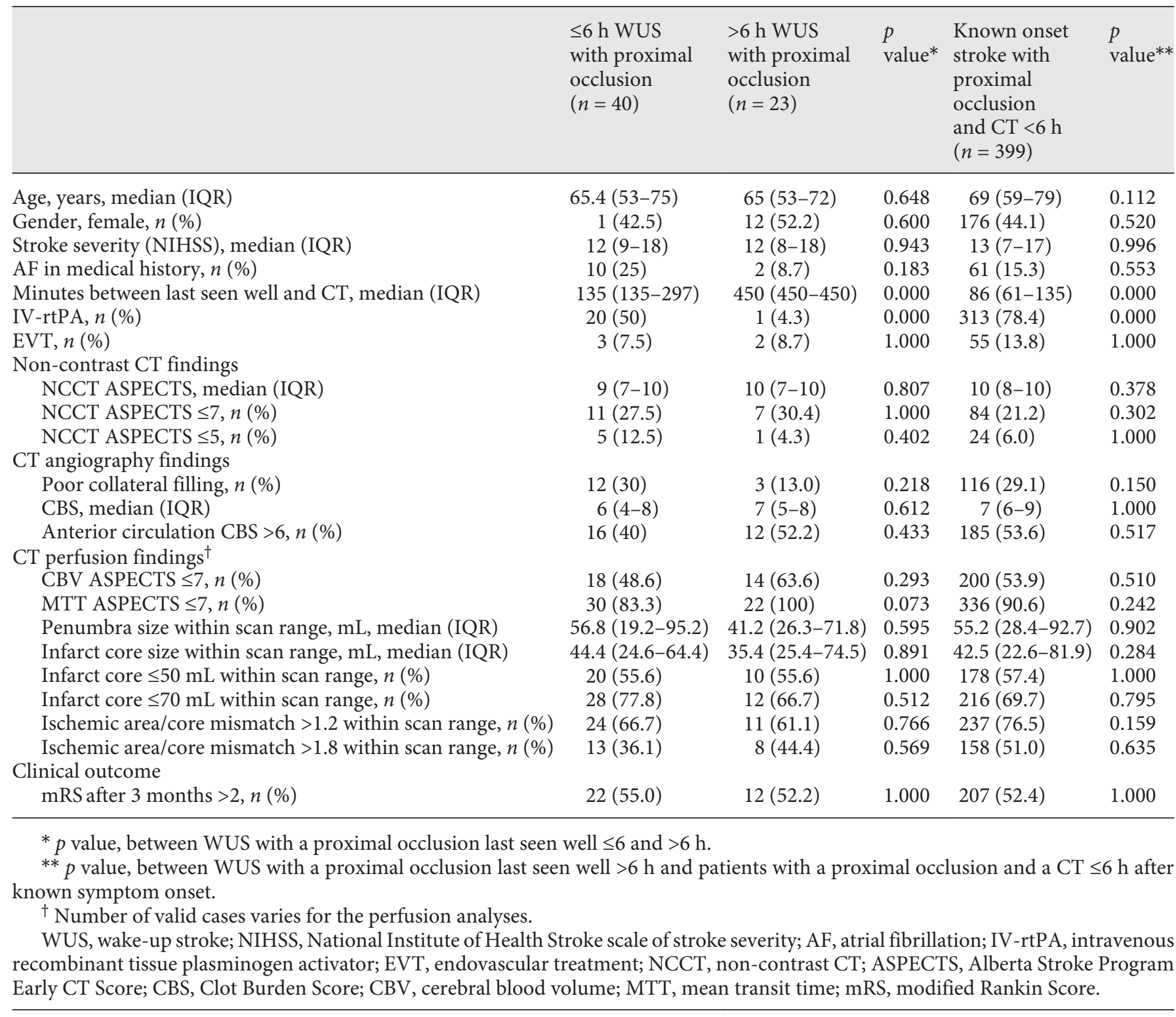

er ASPECTS). However, the majority (75\%) of WUS patients had a favorable ASPECTS and good collateral filling on CTA. This suggests that they may benefit from IV-rtPA treatment. No significant differences were seen when comparing WUS patients with a proximal occlusion of the anterior circulation last seen well $>6 \mathrm{~h}$ to patients with a proximal occlusion and CT imaging within $6 \mathrm{~h}$ after a known time of stroke symptom onset, that is, eligible for EVT. More than half (57\%) of the WUS patients with a proximal occlusion who were last seen well
$>6 \mathrm{~h}$ had favorable imaging characteristics, with only minor ischemic changes (ASPECTS $>7$ ) and good collateral filling. Our findings suggest that CT imaging can be used to select WUS patients that are potential candidates for IV-rtPA or EVT.

In a previous study, no significant differences were shown in clinical features between patients with a WUS and patients with a known onset time of their stroke [5, $6,9,21,22]$. In another study, WUS patients were not at increased odds for unfavorable functionality or in-hospi- 


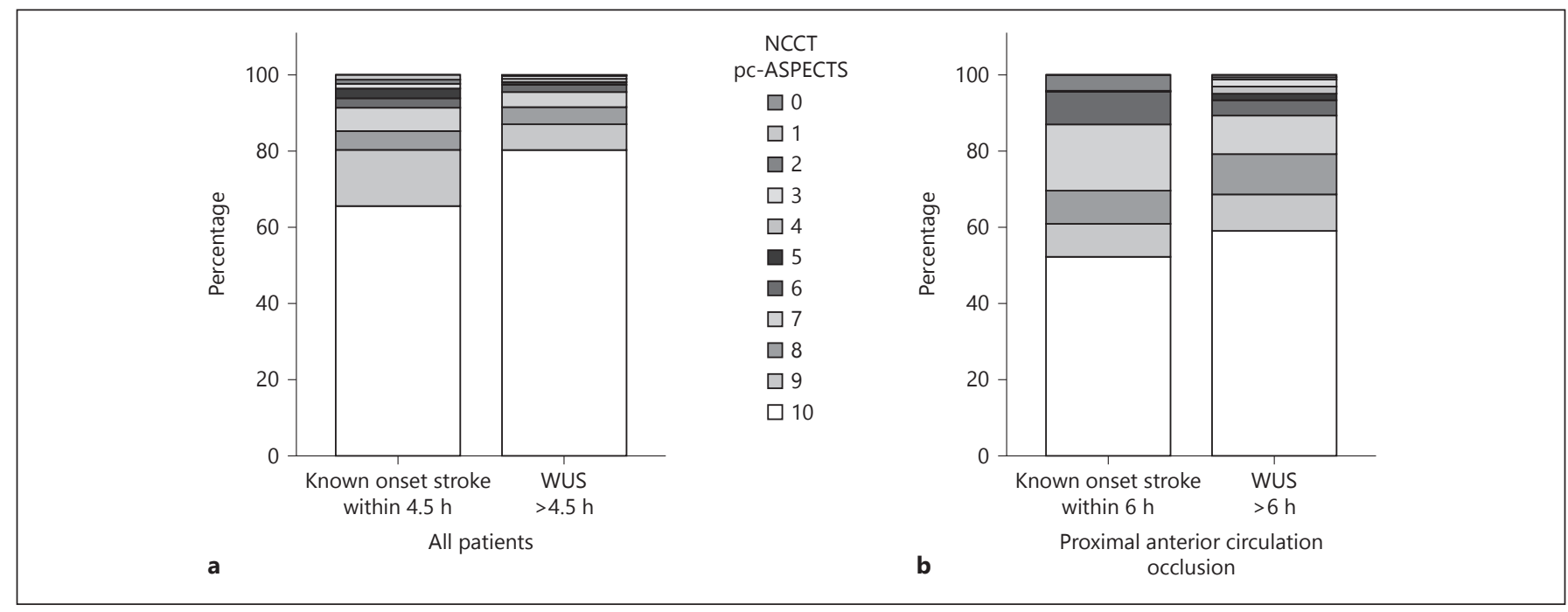

Fig. 1. Spread of pc-ASPECTS: (a) patients with symptom onset within $4.5 \mathrm{~h}$ before imaging and $>4.5 \mathrm{~h}$ WUS patients; (b) patients with symptom onset within $6 \mathrm{~h}$ before imaging and a proximal an- terior circulation occlusion and $>6 \mathrm{~h}$ WUS patients with a proximal anterior circulation occlusion. ASPECTS, Alberta Stroke Program Early CT Score; WUS, wake-up stroke.
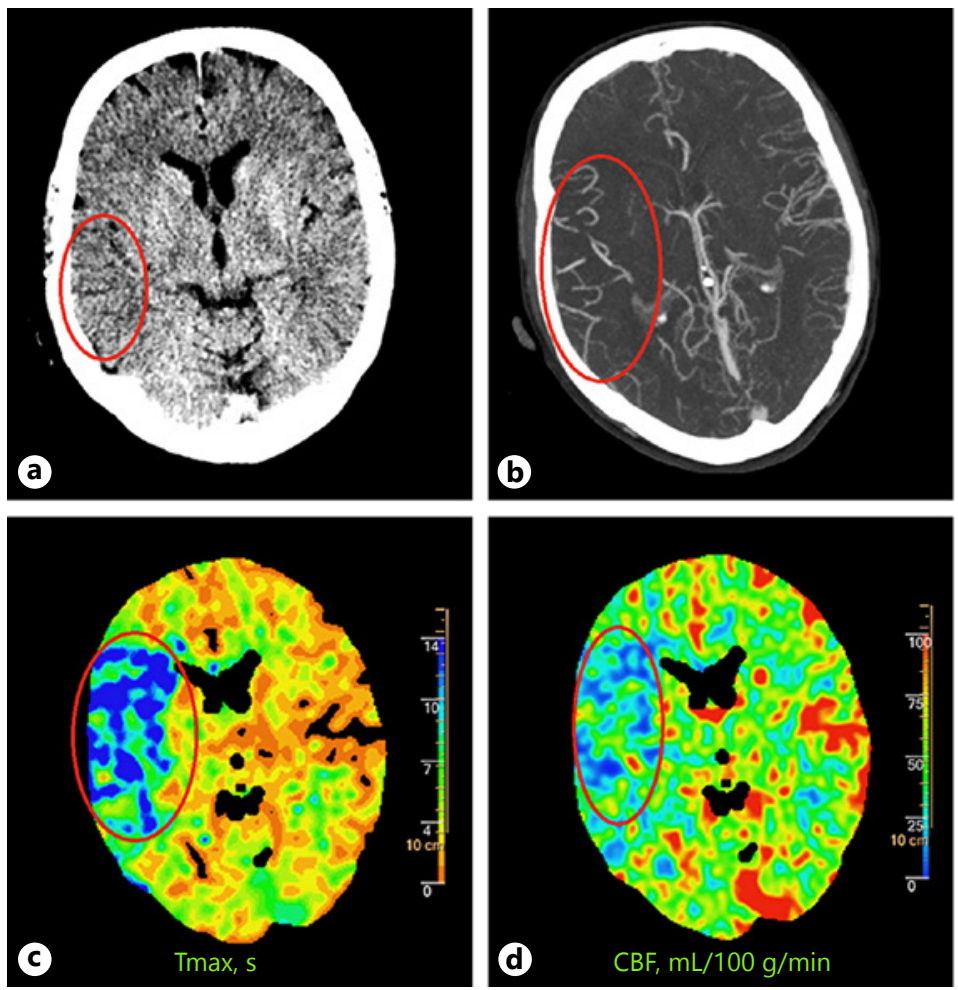

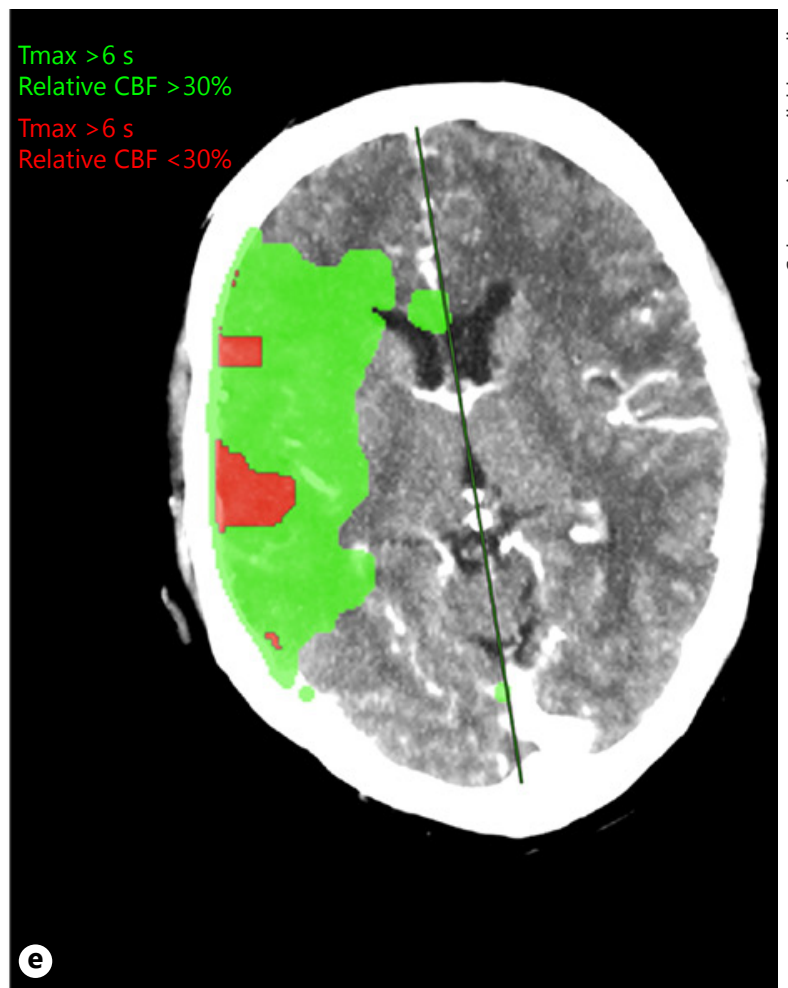

summary map (e) shows the area of Tmax $>6 \mathrm{~s}$ (green) and the area of $>30 \%$ relative CBF decrease (red). The patient was not treated with IV-rtPA but showed good recovery with a 90-day mRS of 2 . WUS, wake-up stroke; NCCT, non-contrast CT; ASPECTS, Alberta Stroke Program Early CT Score; CTA, CT angiography; MCA, middle cerebral artery; CTP, CT-perfusion; IV-rtPA, intravenous tissue plasminogen activator; mRS, modified Rankin Scale. 

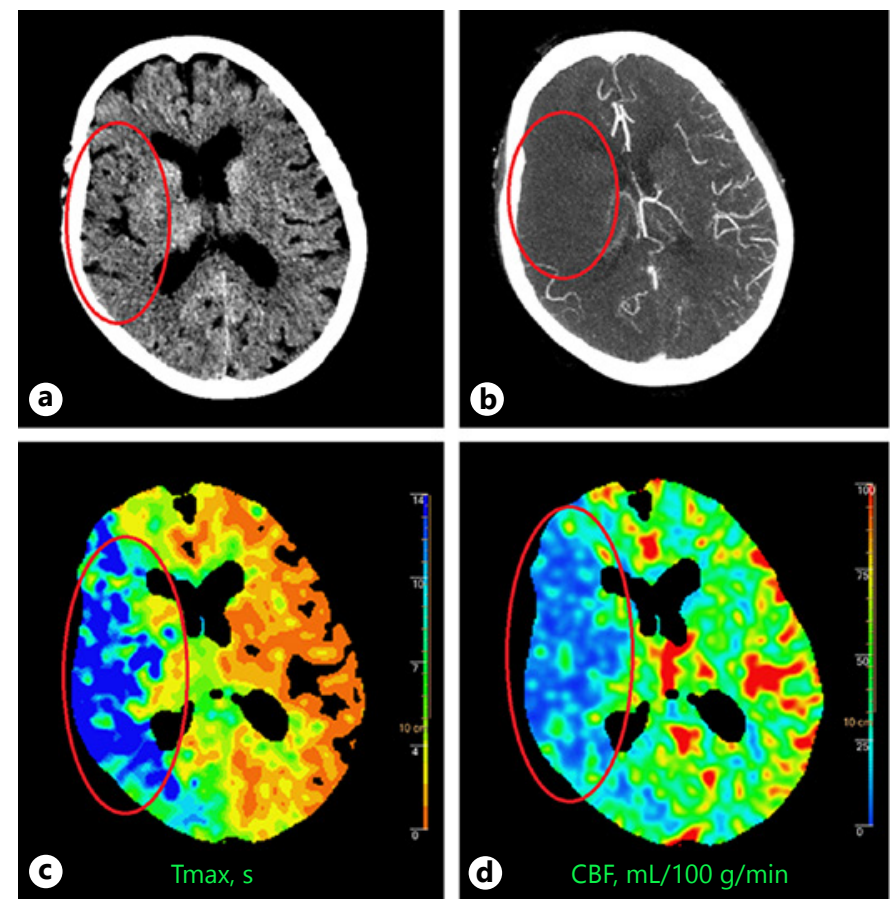

Fig. 3. Eighty-six-year-old female patient imaged within $4.5 \mathrm{~h}$ after symptom onset. a The NCCT showed a large hypodense area (red oval) in the right hemisphere with ASPECTS 1. b The CTA showed poor collateral filling (red oval) and a proximal occlusion in the distal ICA and M1 segment (different slice). The CTP showed (c) a large area with an increased Tmax (red oval), and (d) a large area with decreased CBF (red oval). The CTP summary map (e) shows

tal mortality after adjustment for age, NIHSS score on admission, and IV-rtPA use [5]. In one study comparing patients imaged within $4.5 \mathrm{~h}$ after symptom onset in WUS patients, WUS patients had lower pc-ASPECTS scores comparable to our results [22]. Studies that compared WUS patients to patients with a known time to symptom onset of $<3 \mathrm{~h}$ showed no difference in ischemic changes on NCCT findings $[9,23]$. The WUS patients underwent imaging at a mean of $7.5 \mathrm{~h}$ after last seen well. An additional comparison between WUS patients and patients with unknown onset time showed that WUS patients have significantly less ischemic changes than patients with an unknown time of stroke onset [23]. This difference suggests that the stroke in WUS patients has only just occurred and caused the patient to wake up. The time since symptom onset may therefore be highly overestimated in WUS patients when using the time since the patient was last seen well. Our findings support this hypothesis.

A recent study selected WUS patients with a small infarct core and a penumbra size $>20 \%$ of the ischemic area

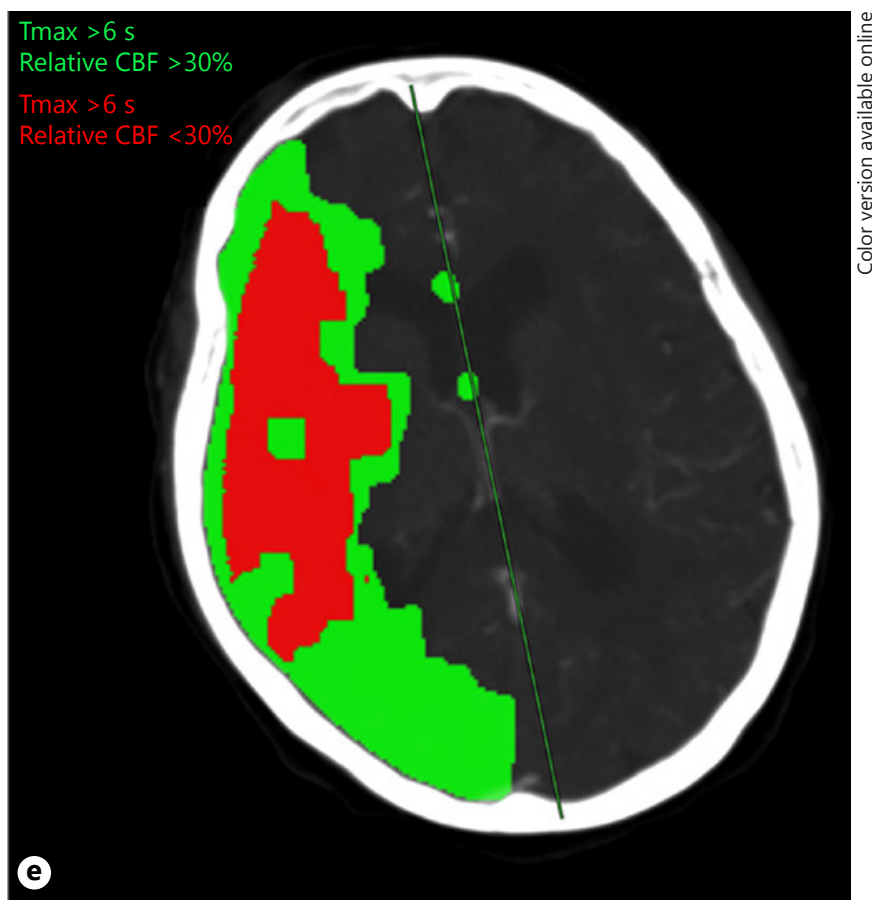

the area of Tmax $>6 \mathrm{~s}$ (green) and the area of $>30 \%$ relative CBF decrease (red). The patient was treated with IV-rtPA and died within 90 days. NCCT, non-contrast CT; ASPECTS, Alberta Stroke Program Early CT Score; CTA, CT angiography; ICA, intracranial carotid artery; CTP, CT-perfusion; IV-rtPA, intravenous tissue plasminogen activator.

on CTP for IV-rtPA treatment [19]. The investigators compared safety of IV-rtPA therapy and clinical outcome between WUS patients and patients treated with IV-rtPA within $4.5 \mathrm{~h}$ of symptom onset [19]. There was no significant difference in functional outcome after 3 months or in incidence of intracranial hemorrhage between the 2 groups. Nearly all of our $>4.5 \mathrm{~h}$ WUS patients had a penumbra size $>20 \%(98.7 \%$ at the ASPECTS levels and 98.5\% within the whole scan range) and therefore may have been eligible for IV-rtPA.

Several randomized trials have recently shown benefit of EVT in patients with a proximal occlusion (intracranial carotid artery-M2). Three of these trials used the ASPECTS as an additional inclusion criterion for treatment selection, with two of them including patients with an ASPECTS $>5$ and one with ASPECTS $>6[14,24,25]$. Only the MR CLEAN trial did not use additional imaging criteria. A subgroup analysis of MR CLEAN showed that NCCT ASPECTS 5-7 patients can be safely treated with EVT [26]. According to these results, the vast majority of the WUS patients with a proximal anterior circulation oc- 
clusion in our study ( $96 \%$ with ASPECTS >5) would have been eligible for EVT. Several trials used perfusion imaging as an imaging inclusion criterion [4, 20, 24]. Two studies included patients for EVT randomization if the mismatch ratio between critical hypoperfusion and the infarct core was more than $1.2[4,20]$ and another with a mismatch of more than 1.8 [3]. Of the $>6 \mathrm{~h}$ WUS patients with a proximal occlusion in our study, 61 and $44 \%$ fulfilled these criteria, and therefore would be eligible for EVT. The third study used an infarct core of $<50 \mathrm{~mL}$ on $\mathrm{CTP}$ as an inclusion criterion for patients with an M1 occlusion arriving within $24 \mathrm{~h}$ after symptom onset. In our population, $56 \%$ of WUS patients last seen well $>6 \mathrm{~h}$ had an infarct core volume $<50 \mathrm{~mL}$. Our volume estimates were however limited to the scan range and may therefore be an underestimation.

Our data were collected before the general application of EVT. Surprisingly, EVT and clinical outcome were not different between WUS patients with a proximal occlusion of the anterior circulation and last seen well $>6 \mathrm{~h}$ and patients with a proximal occlusion and CT imaging within $6 \mathrm{~h}$ after known symptom onset. With current guidelines, many more patients with a proximal occlusion would have been treated with EVT within and beyond $6 \mathrm{~h}$ after symptom onset.

An important strength of our study is the size of this prospectively collected cohort. All patients underwent NCCT, CTA, and CTP at admission and structured clinical evaluation. Patients who were last seen well $>9 \mathrm{~h}$ were excluded. This may explain why we found a relatively low time between last seen well and CT for the WUS patients and a relatively low percentage of WUS patients compared to other cohorts [7]. However, the cohort most similar to ours also found similar results [23].

There are several limitations to the study that need to be taken into account. First, the comparisons in the study between WUS patients and patients with a known onset time of stroke symptoms was based on anamnestic determination of the time since last seen well. This may have introduced some error, as seen in the estimated times of the WUS patients in the 6-9 h group. Second, for some variables, the number of patients with a positive finding was low, especially in the analyses of patients with a proximal occlusion. This may also introduce a source of error. Third, a large part of the included patients did not show imaging abnormalities on admission. This could imply that TIA and stroke mimics were included. However, all patients included in the analysis had an NIHSS at baseline of $\geq 2$ or 1 if an indication for
IV-rtPA is present (e.g., isolated aphasia) [10]. They therefore had suspected stroke and an indication for IV-rtPA. Moreover, the detection of ischemia on CT perfusion is not $100 \%$; small infarcts and infarcts outside the scan range can be missed [27]. Since this is true for the entire study population, it should not have influenced the analyses.

\section{Conclusions}

There were only small differences between clinical and imaging characteristics of WUS patients and patients with a known onset time of stroke symptoms. This supports the hypothesis that patients with WUS may wake up from their stroke symptoms. Most WUS patients have only limited ischemic findings (ASPECTS $>7$ ) and good collaterals, which may make them eligible for IV-rtPA treatment. Most WUS patients with a proximal anterior circulation occlusion have good collateral filling and no severe ischemia (ASPECTS $<5$ ) and may therefore be eligible for EVT.

\section{Acknowledgments}

The DUST investigators are Majoie CB, Roos YB, Academic Medical Center, Amsterdam, The Netherlands; Duijm LE, Keizer K, Catharina Hospital, Eindhoven, The Netherlands; van der Lugt A, Dippel DW, Erasmus Medical Center, Rotterdam, The Netherlands; Droogh-de Greve KE, Bienfait HP, Gelre Hospitals, Apeldoorn, The Netherlands; van Walderveen MA, Wermer MJ, Leiden University Medical Center, Leiden, The Netherlands; Lycklama à Nijeholt GJ, Boiten J, Medical Center Haaglanden, The Hague, The Netherlands; Duyndam D, Kwa VI, Onze Lieve Vrouwe Gasthuis, Amsterdam, The Netherlands; Meijer FJ, van Dijk EJ, Radboud University Nijmegen Medical Centre, Nijmegen, The Netherlands; Kesselring FO, Hofmeijer J, Rijnstate Hospital, Arnhem, The Netherlands; Vos JA, Schonewille WJ, St. Antonius Hospital, Nieuwegein, The Netherlands; van Rooij WJ, de Kort PL, St. Elisabeth Hospital, Tilburg, The Netherlands; Pleiter CC, Bakker SL, St. Franciscus Hospital, Rotterdam, The Netherlands; Bot J, Visser MC, VU Medical Center, Amsterdam, The Netherlands; Velthuis BK, van der Schaaf IC, Dankbaar JW, Mali WP, van Seeters T, Horsch AD, Niesten JM, Biessels GJ, Kappelle LJ, Luitse MJ, van der Graaf Y, University Medical Center Utrecht, Utrecht, The Netherlands.

\section{Disclosure Statement}

This study was supported by grants from the Netherlands Heart Foundation (grant numbers 2008 T034 and 2012 T061) and the Nuts Ohra Foundation (grant number 0903-012). 


\section{References}

1 Hacke W, Kaste M, Bluhmki E, Brozman M, Davalos A, Guidetti D, et al: Thrombolysis with alteplase 3 to 4.5 hours after acute ischemic stroke. N Engl J Med 2008;359:13171329.

2 Saver JL, Goyal M, van der Lugt A, Menon BK, Majoie CB, Dippel DW, et al: Time to treatment with endovascular thrombectomy and outcomes from ischemic stroke: a meta-analysis. JAMA 2016;316:1279-1288.

3 Albers GW, Marks MP, Kemp S, Christensen S, Tsai JP, Ortega-Gutierrez S, et al: Thrombectomy for stroke at 6 to 16 hours with selection by perfusion imaging. N Engl J Med 2018 378:708-718

4 Nogueira RG, Jadhav AP, Haussen DC, Bonafe A, Budzik RF, Bhuva P, et al: Thrombectomy 6 to 24 hours after stroke with a mismatch between deficit and infarct. N Engl J Med 2018;378:11-21.

5 Denny MC, Boehme AK, Dorsey AM, George $\mathrm{AJ}$, Yeh $\mathrm{AD}$, Albright $\mathrm{KC}$, et al: Wake-up strokes are similar to known-onset morning strokes in severity and outcome. J Neurol Neurol Disord 2014;1:pii:102.

6 Mackey J, Kleindorfer D, Sucharew $H$, Moomaw CJ, Kissela BM, Alwell K, et al: Population-based study of wake-up strokes. Neurology 2011;76:1662-1667.

7 Rubin MN, Barrett KM: What to do with wake-up stroke. Neurohospitalist 2015;5: 161-172.

8 Thomalla G, Fiebach JB, Ostergaard L, Pedraza S, Thijs V, Nighoghossian N, et al: A multicenter, randomized, double-blind, placebocontrolled trial to test efficacy and safety of magnetic resonance imaging-based thrombolysis in wake-up stroke (WAKE-UP). Int J Stroke 2014;9:829-836.

9 Roveri L, La Gioia S, Ghidinelli C, Anzalone N, De Filippis C, Comi G: Wake-up stroke within 3 hours of symptom awareness: imaging and clinical features compared to standard recombinant tissue plasminogen activator treated stroke. J Stroke Cerebrovasc Dis 2013;22:703-708.

10 van Seeters T, Biessels GJ, Kappelle LJ, van der Schaaf IC, Dankbaar JW, Horsch AD, et al:
The prognostic value of CT angiography and CT perfusion in acute ischemic stroke. Cerebrovasc Dis 2015;40:258-269.

11 van Seeters T, Biessels GJ, van der Schaaf IC Dankbaar JW, Horsch AD, Luitse MJ, et al: Prediction of outcome in patients with suspected acute ischaemic stroke with CT perfusion and CT angiography: the Dutch acute stroke trial (DUST) study protocol. BMC Neurol 2014;14:37.

12 Barber PA, Demchuk AM, Zhang J, Buchan AM: Validity and reliability of a quantitative computed tomography score in predicting outcome of hyperacute stroke before thrombolytic therapy. ASPECTS Study Group. Alberta Stroke Programme Early CT Score. Lancet 2000;355:1670-1674.

13 Puetz V, Sylaja PN, Coutts SB, Hill MD, Dzialowski I, Mueller P, et al: Extent of hypoattenuation on CT angiography source images predicts functional outcome in patients with basilar artery occlusion. Stroke 2008;39:2485-2490.

14 Goyal M, Demchuk AM, Menon BK, Eesa M, Rempel JL, Thornton J, et al: Randomized assessment of rapid endovascular treatment of ischemic stroke. N Engl J Med 2015;372: 1019-1030.

15 Kudo K, Sasaki M, Ogasawara K, Terae S, Ehara S, Shirato H: Difference in tracer delayinduced effect among deconvolution algorithms in CT perfusion analysis: quantitative evaluation with digital phantoms. Radiology 2009;251:241-249.

16 van Seeters T, Biessels GJ, Niesten JM, van der Schaaf IC, Dankbaar JW, Horsch AD, et al: Reliability of visual assessment of non-contrast CT, CT angiography source images and CT perfusion in patients with suspected ischemic stroke. PLoS One 2013;8:e75615

17 Campbell BC, Christensen S, Levi CR, Desmond PM, Donnan GA, Davis SM, et al: Cerebral blood flow is the optimal CT perfusion parameter for assessing infarct core. Stroke 2011;42:3435-3440.

18 Olivot JM, Mlynash M, Thijs VN, Kemp S, Lansberg MG, Wechsler L, et al: Optimal Tmax threshold for predicting penumbral tissue in acute stroke. Stroke 2009;40:469-475.
19 Morelli N, Rota E, Immovilli P, Cosottini M, Giorgi-Pierfranceschi M, Magnacavallo A, et al: Computed tomography perfusion-based thrombolysis in wake-up stroke. Intern Emerg Med 2015;10:977-984.

20 Campbell BC, Mitchell PJ, Kleinig TJ, Dewey HM, Churilov L, Yassi N, et al: Endovascular therapy for ischemic stroke with perfusionimaging selection. N Engl J Med 2015;372: 1009-1018.

21 Tan IY, Demchuk AM, Hopyan J, Zhang L, Gladstone D, Wong K, et al: CT angiography clot burden score and collateral score: correlation with clinical and radiologic outcomes in acute middle cerebral artery infarct. AJNR Am J Neuroradiol 2009;30:525-531.

22 Costa R, Pinho J, Alves JN, Amorim JM, Ribeiro M, Ferreira C: Wake-up stroke and stroke within the therapeutic window for thrombolysis have similar clinical severity, imaging characteristics, and outcome. J Stroke Cerebrovasc Dis 2016;25:511-514

23 Todo K, Moriwaki H, Saito K, Tanaka M, Oe $\mathrm{H}$, Naritomi H: Early CT findings in unknown-onset and wake-up strokes. Cerebrovasc Dis 2006;21:367-371.

24 Jovin TG, Chamorro A, Cobo E, de Miquel MA, Molina CA, Rovira A, et al: Thrombectomy within 8 hours after symptom onset in ischemic stroke. N Engl J Med 2015;372: 2296-2306

25 Saver JL, Goyal M, Bonafe A, Diener HC, Levy EI, Pereira VM, et al: Stent-retriever thrombectomy after intravenous t-PA vs. t-PA alone in stroke. N Engl J Med 2015;372:2285-2295.

26 Yoo AJ, Berkhemer OA, Fransen PS, van den Berg LA, Beumer D, Lingsma HF, et al: Effect of baseline Alberta Stroke Program Early CT Score on safety and efficacy of intra-arterial treatment: a subgroup analysis of a randomised phase 3 trial (MR CLEAN). Lancet Neurol 2016;15:685-694.

27 Niesten JM, van der Schaaf IC, van der Graaf Y, Kappelle LJ, Biessels GJ, Horsch AD, et al: Predictive value of thrombus attenuation on thin-slice non-contrast CT for persistent occlusion after intravenous thrombolysis. Cerebrovasc Dis 2014;37:116-122. 